\title{
Inmunoterapia genética con células dendríticas para el tratamiento del cáncer
}

\section{Dendritic cells in cancer immunotherapy}

\author{
M. Gato, T. Liechtenstein, I. Blanco-Luquín, M.I. Zudaire, G. Kochan, D. Escors
}

\section{RESUMEN}

Desde comienzos del siglo XX, los científicos han intentado aprovechar las actividades naturales del sistema inmunológico para curar el cáncer. Sin embargo, las inmunoterapias no han dado el resultado clínico que podría haberse esperado. De hecho, lo tratamientos anti-neoplásicos clásicos como la cirugía, la radioterapia y la quimioterapia siguen consistiendo en la primera línea de tratamiento. Aun así, existe un gran número de evidencias experimentales sobre la inmunogenicidad de las células cancerosas. Sin embargo, la activación efectiva de las respuestas $\mathrm{T}$ anti-cancerosas depende estrechamente de la presentación eficiente de antígenos tumorales por parte de células presentadoras de antígeno profesionales, como las células dendríticas (dendritic cells, DC). Aunque se han desarrollado un gran número de estrategias para reforzar las funciones de presentación de antígeno de las DC, la inmunoterapia como tratamiento anti-neoplásico todavía no es tan efectiva como esperaríamos de acuerdo con los resultados obtenidos en modelos preclínicos durante las últimas décadas. En este trabajo no pretendemos revisar exhaustivamente la inmunoterapia con DC, un campo ampliamente extenso y tratado en otras revisiones especializadas. Aquí se exponen la experiencias que nuestro grupo ha llevado a cabo durante la última década modificando genéticamente a las DC para mejorar su eficacia anti-tumoral.

Palabras clave. Terapia génica. Lentivectores. Inmunología. Células dendríticas.

\begin{abstract}
Since the beginning of the 20th century, biomedical scientists have tried to take advantage of the natural anti-cancer activities of the immune system. However, all the scientific and medical efforts dedicated to this have not resulted in the expected success. In fact, classical antineoplastic treatments such as surgery, radio and chemotherapy are still first line treatments. Even so, there is a quantity of experimental evidence demonstrating that cancer cells are immunogenic. However, the effective activation of anti-cancer T cell responses closely depends on an efficient antigen presentation carried out by professional antigen presenting cells such as DC. Although there are a number of strategies to strengthen antigen presentation by DC, anti-cancer immunotherapy is not as effective as we would expect according to preclinical data accumulated in recent decades. We do not aim to make an exhaustive review of DC immunotherapy here, which is an extensive research subject already dealt with in many specialised reviews. Instead, we present the experimental approaches undertaken by our group over the last decade, by modifying DC to improve their anti-tumour capacities.
\end{abstract}

Keywords. Genetic therapy. Lentiral vectors. Inmunology. Dendritics cells.
Navarrabiomed-Fundación Miguel Servet

Recepción: 24 de noviembre de 2014

Aceptación provisional: 25 de febrero de 2015

Aceptación definitiva: 10 de marzo de 2015

\author{
Correspondencia \\ David Escors \\ Navarrabiomed-Fundación Miguel Servet \\ Recinto hospitalario \\ 31008 Pamplona \\ E-mail: descorsm@navarra.es
}




\section{INTRODUCCIÓN}

La idea de que el sistema inmunitario tiene capacidades anti-cancerosas no es nueva. Paul Ehrlich al comienzo del siglo XX propuso su teoría de vigilancia inmunológica también para el cáncer. Según Ehrlich, las células tumorales aparecían espontáneamente en el organismo y el sistema inmunitario las eliminaba. De hecho, parece ser que la eficacia de los tratamientos clásicos también recae en gran medida en la activación de respuestas inmunológicas tras la liberación de moléculas inmunoestimuladoras procedentes de células necróticas ${ }^{1-5}$.

La eficacia de la inmunoterapia contra el cáncer depende de la inmunogenicidad de las células tumorales para inducir respuestas $\mathrm{T}$ citotóxicas. Por lo tanto, las células cancerosas deberían expresar antígenos inmunogénicos susceptibles de convertirse en dianas terapéuticas. Las primeras inmunoterapias ya en los años 60 se dirigieron contra antígenos virales expresados por virus oncogénicos. Sin embargo, solo un número bajo de cánceres humanos son provocados por infecciones virales. De hecho, la teoría de la etiología viral de los cánceres no podía explicar las respuestas inmunológicas generadas contra tumores inducidos químicamente, o las regresiones espontáneas de cánceres en personas vacunadas contra patógenos comunes o por administración de adyuvantes. Estos resultados demostraban la existencia de antígenos tumorales de origen no viral ${ }^{6}$.

Con el paso del tiempo se descubrió que las células cancerosas acumulaban mutaciones transformantes que resultaban en inestabilidad genética, incremento de supervivencia celular y proliferación incontrolada ${ }^{7-13}$. Muchas de las proteínas afectadas en estas mutaciones son factores de transcripción (c-myc), moléculas de señalización intracelular (ras), reguladores de división celular (Rb) y anti-oncogenes (p53). La proliferación incontrolada y los defectos en la reparación del ADN celular provocan aún más mutaciones, que dan lugar a la expresión aberrante de proteínas celulares (mutadas o no), confiriendo inmunogenicidad a las células cancerosas.

\section{IDENTIFICACIÓN DE ANTÍGENOS TUMORALES HUMANOS}

Desde los años 50, se han identificado un gran número de antígenos tumorales capaces de activar respuestas $\mathrm{T}$ citotóxicas ${ }^{6}$, por ejemplo, la sobreexpresión de tirosinasa en melanomas ${ }^{14-20}$. En los años $90 \mathrm{se}$ clonaron las proteínas relacionadas con la tirosinasa 1 y 2 (TRP-1, TRP-2), ambas sobreexpresadas en melanoma ${ }^{21-25}, \mathrm{y}$ con alto interés terapéutico ${ }^{26,27}$. Los antígenos carcinoembrionarios (CEA) se identificaron indirectamente en los años $60^{28,29}$, identificándose en los 90 varios péptidos antigénicos CD8 y CD4 $4^{30,31}$ utilizados en inmunoterapia humana ${ }^{32}$. Otros antígenos de alto interés son los asociados a melanoma (MAGE), expresados en una gran variedad de cánceres $^{33}$. Estos antígenos contienen múltiples epítopos inmunogénicos utilizados con éxito $^{34}$. El antígeno gp100 se identificó en $1988^{35}$, conteniendo varios epítopos $\mathrm{T}^{19,36}$. NY-ESO-1 se aisló a partir de un carcinoma escamoso de esófago ${ }^{37}$. Dada su frecuente expresión en varios tumores, es uno de los antígenos más relevantes para inmunoterapia humana ${ }^{38,39}$. MART-1 se clonó en 1994 a partir una línea de melanoma humano ${ }^{40}, \mathrm{y}$ se utiliza frecuentemente en vacunas contra melanoma ${ }^{19,20,41,42}$.

En conclusión, los cánceres son ciertamente inmunogénicos, y expresan antígenos tumorales reconocidos por linfocitos T CD4 y CD8 autólogos. Sin embargo, el éxito clínico de la inmunoterapia es sorprendentemente bajo. Los tumores suelen reaparecer tras su escape del sistema inmunitario. Algunos de estos mecanismos incluyen la selección de variantes celulares que han perdido la expresión de los antígenos inmunogénicos, o que han disminuido la expresión de moléculas de presentación de antígenos MHC (major histocompatibility complex molecules, MHC). Adicionalmente, los tumores expanden células inmunosupresoras que favorecen la metástasis y la 
progresión tumoral. Todos estos mecanismos suponen las barreras más importantes a superar en inmunoterapia.

\section{ACTIVACIÓN DE LOS LINFOCITOS T CITOTÓXICOS DURANTE LA PRESENTACIÓN DE ANTÍGENO}

La activación de linfocitos específicos frente a antígenos tumorales es francamente un reto. Estos antígenos se expresan en bajos niveles, lo que causa una presentación subóptima a los linfocitos T. En esta situación, los linfocitos que reconocen estos antígenos se diferencian hacia linfocitos $\mathrm{T}$ reguladores (Tregs) ${ }^{43,44}$. Generalmente, para su activación, los linfocitos reconocen a través de su TCR (receptor del linfocito T) péptidos antigénicos asociados a las moléculas MHC y expuestos en la superficie de las DC. Este reconocimiento no es suficiente para activarlos, y requieren otro tipo de interacciones entre un número de receptores y ligandos en la sinapsis inmunológica. La integración de estas interacciones se denomina co-estimulación (o señal 2). El tipo de citoquinas presentes

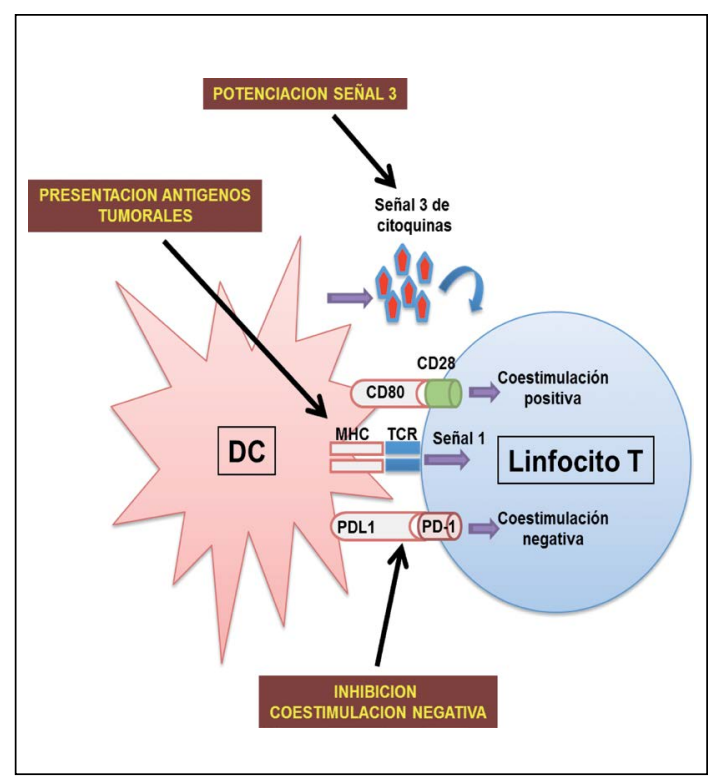

durante la presentación de antígenos proporciona una tercera señal necesaria para la diferenciación de los linfocitos $\mathrm{T}$ en distintos tipos (Fig.1).

En general, las DC inmaduras son poco inmunogénicas dada la baja expresión de moléculas co-estimuladoras en su superficie. Sin embargo, la expresión de estas moléculas aumenta fuertemente tras el reconocimiento de moléculas derivadas de patógenos. En este proceso de "maduración" de las $\mathrm{DC}^{45}$ se transforman en fuertemente inmunogénicas. En el caso de los antígenos tumorales, los péptidos tumorales suelen derivarse de proteínas endógenas expresadas aberrantemente, o con mutaciones. Por lo tanto, en condiciones fisiológicas no existen moléculas derivadas de patógenos que activen a las DC. Además, la frecuencia de los linfocitos T específicos de antígenos endógenos es baja, ya que se eliminan en el timo durante su diferenciación. Las células $\mathrm{T}$ autoreactivas circulantes que han escapado de la delección clonal en el timo poseen TCRs de baja afinidad, o se han diferenciado a Tregs para preservar la tolerancia inmunológica ${ }^{46}$.

Figura 1. Presentación de antígenos a los linfocitos T. En el esquema se muestra una célula dendrítica (DC) presentando un péptido antigénico unido a una molécula MHC (indicado por la flecha) al linfocito T de la derecha a través de su TCR. Esta presentación del péptido genera una señal en el linfocito (señal 1) que no es suficiente para activarlo. Para ello, es necesaria la unión de moléculas coestimuladoras/coinhibitorias presentes en la superficie de la DC con sus ligandos correspondientes en el linfocito T. En la figura se muestra una coestimulación positiva (CD80 con CD28) en la zona superior y una interacción coinhibitoria (PD-L1 con PD-1) como se muestra en la parte inferior. Además, la presencia de citoquinas secretadas durante la presentación de antígeno proporcionará una tercera señal al linfocito T para su activación y diferenciación. Para incrementar las capacidades activadoras de las DCs, habría que potenciar ciertas señales de citoquinas (señalado con una flecha en la zona superior), e inhibir interacciones inactivadoras (señalado con una flecha en la zona inferior). 


\section{INMUNOTERAPIA CONTRA EL CÁNCER CON CÉLULAS DENDRÍTICAS}

Las DC son las células presentadoras de antígeno más eficaces e ideales para la inmunoterapia. Las DC se diferencian con facilidad a partir de médula ósea de ratón utilizando GM-CSF recombinante, y también de monocitos humanos ${ }^{47,48}$. Estos métodos de producción ex vivo aceleraron el progreso de la inmunoterapia basada en DC, ya que su número dejó de ser un factor limitante. Las DC diferenciadas son fenotípica y funcionalmente inmaduras, lo que facilita su manipulación. Como uno de los grandes problemas de la inmunoterapia contra el cáncer es la activación ineficiente de células $\mathrm{T}$ efectoras, la vacunación con DC parece de las mejores opciones. La potenciación de sus capacidades endógenas de presentación de antígenos podría romper la tolerancia natural contra antígenos tumorales endógenos.

La producción a gran escala de DC permitió su aplicación directa en vacunación, tras la incubación con antígenos tumorales, ya sea en forma de péptidos o a partir de lisados tumorales ${ }^{49}$. Otra ventaja de la producción ex vivo de DC es la facilidad con las que se pueden modificar genéticamente con vectores virales y no virales $^{45,49-51}$. Además, como su estado de maduración se puede controlar con relativa facilidad ${ }^{1,41,51-53}$, las DC son ideales para inmunoterapias. Las DC generadas ex vivo se han utilizado para generar respuestas $\mathrm{T}$ contra agentes infecciosos ${ }^{52,54-57}$ y cáncer 41,49,52,58-60. Los resultados preclínicos en inmunoterapia con DC generadas ex vivo han proporcionado datos muy relevantes ${ }^{49}$. Sin embargo, en algunos casos estos resultados no se han trasladado con el éxito esperado a pacientes humanos ${ }^{61-63}$. Para poder responder a esta aparente contradicción, nuestro grupo de investigación ha estudiado las rutas de señalización intracelular en DC durante los últimos 6 años, para controlar las funciones inmunogénicas de las DC utilizando herramientas de terapia génica.

\section{ACTIVACIÓN CONSTITUTIVA DE RUTAS DE SEÑALIZACIÓN INTRACELULAR EN CÉLULAS DENDRÍTICAS}

Durante una infección, las moléculas derivadas de los patógenos se unen a receptores en las DC que reconocen patrones moleculares de patógenos, causando su maduración. Ese es el papel que juegan los adjuvantes en la formulación de las vacunas clásicas. En nuestro grupo, postulamos que podría ser posible modificar las actividades de las DC mediante la activación de rutas de señalización intracelular controladas por este tipo de receptores de patrones moleculares de patógenos, mediante modificación genética.

Cuando estos receptores se unen a sus ligandos, activan una red de cascadas de señalización intracelular que convergen en la activación de un número relativamente pequeño de rutas. De éstas, las cuatro principales son la ruta NF-kB, las proteína kinasas activadas por mitógenos (MAPK) y los factores reguladores de interferón (IRF) (Fig. 2A). Estas rutas regulan la expresión de MHC y moléculas coestimuladoras, así como la producción de citoquinas. Aun así, estas rutas también activan mecanismos reguladores terminadores de estas señales (negative feedback) ${ }^{64,65}$. En situaciones fisiológicas, estos mecanismos inhibitorios aseguran un control de la inflamación que protege al organismo. Sin embargo, en el contexto de la inmunoterapia contra el cáncer, estos mecanismos son contraproducentes.

\section{MODULACIÓN DE RUTAS INTRACELULARES DE SEÑALIZACIÓN PARA CONTROLAR LAS FUNCIONES DE LAS CÉLULAS DENDRÍTICAS}

Nuestro grupo de investigación decidió expresar mutantes constitutivamente activos de estas rutas de señalización, eligiendo moléculas resistentes a la actividad de proteínas inhibitorias como las fosfatasas de MAPK. 
A)

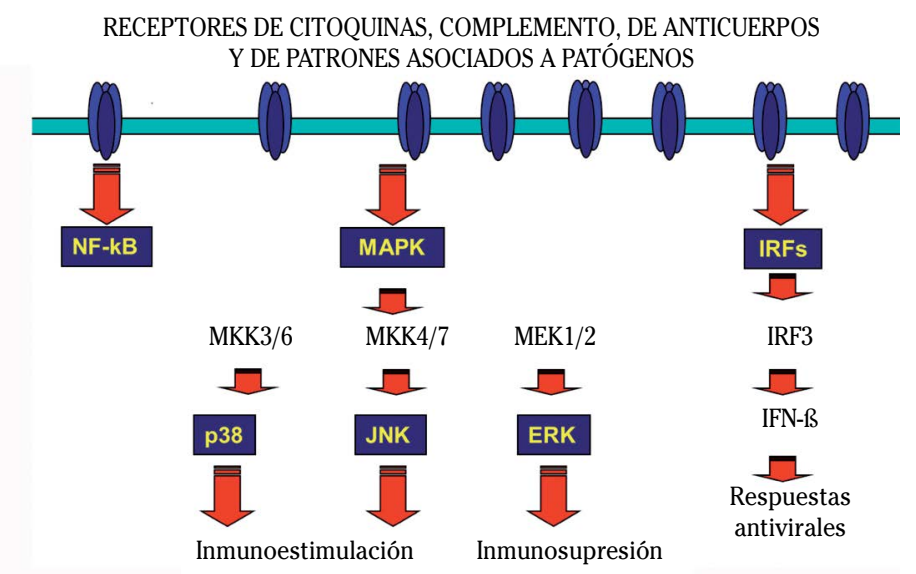

B)

)

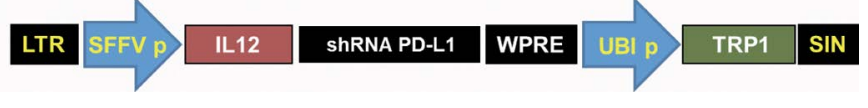

Figura 2. Rutas de señalización intracelular e inmunoterapia génica. (A) En el esquema se muestran las rutas de señalización intracelular que controlan la actividad de las DCs, divididas en NF-kB, las MAPKs y los IRFs. Las rutas NF-kB y MAPKs p38 y JNK1 son inmunoestimuladoras, mientras que la MAPK ERK es inhibitoria. La ruta IRF3 está involucrada en respuestas anti-virales. (B) Esquema de un lentivector utilizado por el laboratorio como vacuna genética contra melanoma. El lentivector está flanqueado por las repeticiones largas terminales (LTR) y contiene dos promotores, el promotor del virus de bazo formador de placas (SFFV, spleen focus-forming virus) y el promotor de ubiquitina humana, tal y como se indica en las flechas. Este lentivector expresa el gen de la interleucina 12, y el antígeno de melanoma TRP1. Además contiene un RNA silenciador contra PD-L1, una proteína que inhibe la activación de los linfocitos T.

Una de las primeras rutas que se modularon genéticamente en DC fue la ruta de NF-kB, una familia de factores de transcripción que transactivan un gran número de genes inflamatorios. La expresión de la proteína de herpesvirus vFLIP (un activador constitutivo de NF-kB) con lentivectores resultó en maduración de las $\mathrm{DC}^{66}$, y se demostró un incremento en supervivencia en un modelo de ratón de linfoma utilizando estas DC como vacunas celulares ${ }^{66}$.

La ruta de las MAPK se divide en tres clases/ p38, c-jun N-terminal kinases (JNK) y kinasas reguladas por señales extracelulares (ERK). Decidimos comprobar los efectos de la activación constitutiva de
MAPK p38. Para ello expresamos en DC con lentivectores un mutante de la MAPK MKK6 que fosforilaba constitutivamente a p38, resistente a las fosfatasas ${ }^{41}$. La vacunación con lentivectores expresando este mutante estimuló significativamente las repuestas $\mathrm{T}$ contra un antígeno modelo no tumoral, y contra NY-ESO-1 en un modelo humanizado de ratón ${ }^{41}$. La activación genética de p38 en DC humanas también estimuló la proliferación de linfocitos CD8 específicos para MART-1. Estas vacunas lentivirales mostraron eficacia como terapia contra linfoma en un modelo de ratón ${ }^{41}$. De una manera similar se activó la ruta JNK1, mejorando de nuevo las respuestas $\mathrm{T}$, aunque no lle- 
gamos a probarla como terapia en modelos preclínicos de cáncer ${ }^{41}$.

También expresamos con lentivectores un mutante de MEK1 que interfería con la activación por fosforilación de ERK en DC. Pensamos que al ser la ruta ERK inmunosupresora, su interferencia podría estimular las funciones de las DC. Y así fue. La inhibición de ERK en DC incrementó sustancialmente las respuestas $\mathrm{T}$ en modelos de ratón, y en combinación con un RNA silenciador de la molécula PD-L1 resultó muy eficaz como terapia anti-linfoma en un modelo de ratón ${ }^{52,58,67}$.

\section{MODULACIÓN DE LA COESTIMULACIÓN PARA MEJORAR LAS RESPUESTAS INMUNITARIAS CONTRA EL CÁNCER}

Recientemente se han desarrollado terapias con anticuerpos bloqueantes de la interacción entre PD-L1 (expresado con cierta frecuencia en tumores) con PD-1 expresado en la superficie de los linfocitos $\mathrm{T}$. Esta interacción es fuertemente inhibitoria, y se ha demostrado que la inmunoterapia puede llegar a ser muy efectiva contrarrestándola con anticuerpos. Este es un tema muy extenso y prometedor desde un punto de vista terapéutico, ampliamente revisado $^{68}$. Nuestro equipo desarrolló, un sistema de lentivectores para expresar una colección de citoquinas junto con un RNA silenciador de PD-L1, y el antígeno tumoral TRP1 (Fig. 2B). Solo la expresión de IL12 en combinación con el silenciamiento de PD-L1 resultó eficaz para el tratamiento de melanoma en ratón ${ }^{67}$. Esto era en parte debido a las propiedades anti-immunosupresoras de IL12 en las células mieloides supresoras (myeloid-derived suppressor cells, o MDSC $)^{67}$.

\section{CONSIDERACIONES FINALES}

La inmunoterapia está comenzando a dar resultados significativos recientemen$\mathrm{te}^{69,70}$, pero todavía queda mucho camino por recorrer. Cada vez hay más evidencias experimentales que sugieren que la efica- cia de los tratamientos anti-neoplásicos convencionales recaen en gran parte en la activación colateral del sistema inmunológico $^{2,3}$. La modificación genética de las células presentadoras de antígeno para activarlas constitutivamente podría mejorar su eficacia inmunoestimuladora.

\section{Agradecimientos}

Los autores quisieran agradecer a todo el personal de Navarrabiomed-FMS y al Complejo Hospitalario de Navarra. También agradecer a los organismos y asociaciones que financian nuestro trabajo, incluyendo al Instituto de Salud Carlos III, a BD Bioscience y la Fundación Sandra Ibarra por su apoyo, al Gobierno de Navarra y al Gobierno Vasco por la financiación proporcionada.

\section{BIBLIOGRAFÍA}

1. Arce F, Kochan G, Breckpot K, Stephenson H, Escors D. Selective activation of intracellular signalling pathways in dendritic cells for cancer immunotherapy. Anticancer Agents Med Chem 2012; 12: 29-39.

2. Ареtoh L, Ghiringhelli F, Tesniere A, Obeid M, ORTIZ C et al. Toll-like receptor 4-dependent contribution of the immune system to anticancer chemotherapy and radiotherapy. Nat Med 2007; 13: 1050-1059.

3. Ghiringhelli F, Apetoh L, Tesniere A, Aymeric L, MA Y, ORTIZ C et al. Activation of the NLRP3 inflammasome in dendritic cells induces IL-1beta-dependent adaptive immunity against tumors. Nat Med 2009; 15: 1170-1178.

4. Zitvogel L, Apetoh L, Ghiringhelli F, Kroemer G. Immunological aspects of cancer chemotherapy. Nat Rev Immunol. 2008; 8: 59-73.

5. Ghiringhelli F, Bruchard M, Apetoh L. Immune effects of 5-fluorouracil: Ambivalence matters. Oncoimmunology 2013; 2: e23139.

6. Escors D. Tumour immunogenicity, antigen presentation and immunological barriers in cancer immunotherapy. New J Sci 2014; 5: 2014.

7. BARBACID, M. Oncogenes and human cancer: cause or consequence? Carcinogenesis 1986; 7: 1037-1042.

8. Malumbres M, Barbacid M. Cell cycle kinases in cancer. Curr Opin Genet Dev 2007; 17: 60-65. 
9. Barbacid M, Ortega S, Sotillo R, Odajima J, Martín A, SAntamaría D et al. Cell cycle and cancer: genetic analysis of the role of cyclin-dependent kinases. Cold Spring Harb Symp Quant Biol 2005; 70: 233-240.

10. Santos E, Martin-Zanca D, Reddy EP, Pierotti MA, Della Porta G, Barbacid M. Malignant activation of a K-ras oncogene in lung carcinoma but not in normal tissue of the same patient. Science 1984; 223: 661-664.

11. Iggo R, Gatter K, Bartek J, Lane D, Harris AL. Increased expression of mutant forms of p53 oncogene in primary lung cancer. Lancet 1990; 335: 675-679.

12. Slamon DJ, Boone TC, Seeger RC, Keith DE, Chazin V, LeE HC, Souza LM. Identification and characterization of the protein encoded by the human N-myc oncogene. Science 1986; 232: 768-772.

13. Lee WH, Shew JY, Hong FD, Sery TW, Donoso LA, Young LJ, Bookstein R, LeE EY. The retinoblastoma susceptibility gene encodes a nuclear phosphoprotein associated with DNA binding activity. Nature 1987; 329: 642-645.

14. Fitzpatrick TB, Lerner AB, Calkins E, Summerson, WH. Occurrence of tyrosinase in horse and fish melanomas. Proc Soc Exp Biol Med 1950; 75: 394-398.

15. Pathak MA, Riley FC, Fitzpatrick TB. Melanogenesis in human skin following exposure to long-wave ultraviolet and visible light. J Invest Dermatol 1962; 39: 435-443.

16. Brichard V, Van Pel A, Wölfel T, Wölfel C, De Plaen E, Lethé B et al. The tyrosinase gene codes for an antigen recognized by autologous cytolytic T lymphocytes on HLA-A2 melanomas. J Exp Med 1993; 178: 489-495.

17. Darrow TL, Slingluff CL Jr, Seigler HF. The role of HLA class I antigens in recognition of melanoma cells by tumor-specific cytotoxic T lymphocytes. Evidence for shared tumor antigens. J Immunol 1989; 142: 3329-3335.

18. Topalian SL, Rivoltini L, Mancini M, Markus NR, Robbins PF, Kawakami Y, Rosenberg SA. Human CD4+ T cells specifically recognize a shared melanoma-associated antigen encoded by the tyrosinase gene. Proc Natl Acad Sci U S A 1994; 91: 9461-9465.

19. Tarhini AA, Leng S, Moschos SJ, Yin Y, SAnder C, LiN Y et al. Safety and immunogenicity of vaccination with MART-1 (26-35, 27L), gp100 (209-217, 210M), and tyrosinase (368-376, 370D) in adjuvant with PF-3512676 and GM$\mathrm{CSF}$ in metastatic melanoma. $\mathrm{J}$ Immunother 2012; 35: 359-366.

20. Ribas A, Weber JS, Chmielowski B, Comin-AnDuIX B, Lu D, Douek M et al. Intra-lymph node prime-boost vaccination against Melan A and tyrosinase for the treatment of metastatic melanoma: results of a phase 1 clinical trial. Clin Cancer Res 2011; 17: 2987-2996.

21. Cohen T, Muller RM, Tomita Y, Shibahara S. Nucleotide sequence of the cDNA encoding human tyrosinase-related protein. Nucleic Acids Res 1990; 18: 2807-2808.

22. Jackson IJ, Chambers DM, TSuKamoto K, Copeland NG, Gilbert DJ, Jenkins NA, HEARING V. A second tyrosinase-related protein, TRP-2, maps to and is mutated at the mouse slaty locus. EMBO J 1992; 11: 527-535.

23. Wang RF, Appella E, Kawakami Y, Kang X, RosenBERG SA. Identification of TRP-2 as a human tumor antigen recognized by cytotoxic $\mathrm{T}$ lymphocytes. J Exp Med 1996; 184: 2207 2216.

24. Parkhurst Mr, Fitzgerald EB, Southwood S, Sette A, Rosenberg SA, KawaKami Y. Identification of a shared HLA-A*0201-restricted T-cell epitope from the melanoma antigen tyrosinase-related protein 2 (TRP2). Cancer Res; 58: 4895-4901.

25. Osen W, Soltek S, Song M, Leuchs B, Steitz J, Tüting T, Eichmüller SB, Nguyen XD, SchadenDORF D, PAschen A. Screening of human tumor antigens for CD4 $\mathrm{T}$ cell epitopes by combination of HLA-transgenic mice, recombinant adenovirus and antigen peptide libraries. PLoS One 2010; 5: e14137.

26. Sierro SR, Donda A, Perret R, Guillaume P, YaGITA H, Levy F, Romero P. Combination of lentivector immunization and low-dose chemotherapy or PD-1/PD-L1 blocking primes self-reactive $\mathrm{T}$ cells and induces anti-tumor immunity. Eur J Immunol 2011; 41: 2217-2228.

27. Bronte V, Apolloni E, Ronca R, Zamboni P, OverWiJK WW, Surman DR, Restifo NP, Zanovello P. Genetic vaccination with "self" tyrosinase-related protein 2 causes melanoma eradication but not vitiligo. Cancer Res 2000; 60: 253-258.

28. Gold P, Freedman SO. Demonstration of tumor-specific antigens in human colonic carcinoma by immunological tolerance and absorption techniques. J Exp Med 1965; 121: 439-462.

29. Gold P, Gold M, Freedman SO. Cellular location of carcinoembryonic antigens of the human digestive system. Cancer Res 1968; 28: 13311334.

30. Tsang KY, Zaremba S, Nieroda CA, Zhu MZ, Hamilton JM, Schlom J. Generation of human cytotoxic $\mathrm{T}$ cells specific for human carcinoembryonic antigen epitopes from patients immunized with recombinant vaccinia-CEA vaccine. J Natl Cancer Inst 1995; 87: 982-990. 
31. Bremers AJ, van der Burg SH, Kuppen PJ, Kast WM, van de Velde CJ, Melief CJ. The use of Epstein-Barr virus-transformed B lymphocyte cell lines in a peptide-reconstitution assay: identification of CEA-related HLA-A*0301-restricted potential cytotoxic T-lymphocyte epitopes. J Immunother Emphasis Tumor Immuno 1995; 18: 77-85.

32. Gameiro SR, Jammeh ML, Hodge JW. Cancer vaccines targeting carcinoembryonic antigen: state-of-the-art and future promise. Expert Rev Vaccines 2013; 12: 617-629.

33. Meek DW, Marcar L. MAGE-A antigens as targets in tumour therapy. Cancer Lett 2012; 324: 126-132.

34. Germeau C, Ma W, Schiavetti F, Lurquin C, Henry E, Vigneron $\mathrm{N}$ et al. High frequency of antitumor $\mathrm{T}$ cells in the blood of melanoma patients before and after vaccination with tumor antigens. J Exp Med 2005; 201: 241-248.

35. Vennegoor C, Hageman P, Van Nouhuis H, Ruiter DJ, Calafat J, Ringens PJ, RümKe P. A monoclonal antibody specific for cells of the melanocyte lineage. Am J Pathol 1988; 130: 179-192.

36. Bakker AB, Schreurs MW, de Boer AJ, KaWAKami Y, Rosenberg SA, Adema GJ, Figdor CG. Melanocyte lineage-specific antigen gp100 is recognized by melanoma-derived tumor-infiltrating lymphocytes. J Exp Med 1994; 179: 10051009.

37. Chen YT, Boyer AD, Viars CS, Tsang S, Old LJ, ARdEN KC. Genomic cloning and localization of CTAG, a gene encoding an autoimmunogenic cancer-testis antigen NY-ESO-1, to human chromosome Xq28. Cytogenet Cell Genet. $1997 ; 79: 237-240$.

38. Gnjatic S, Nishikawa H, Jungbluth AA, Güre AO, RitTER G, JÄGER E et al. NY-ESO-1: review of an immunogenic tumor antigen. Adv Cancer Res 2006; 95: 1-30.

39. Robbins PF, Morgan RA, Feldman SA, Yang JC, SHERry RM, DudLEy ME et al. Tumor regression in patients with metastatic synovial cell sarcoma and melanoma using genetically engineered lymphocytes reactive with NY-ESO-1. J Clin Oncol 2011; 29: 917-924.

40. Kahakami Y, Eliyahu S, Delgado CH, Robbins PF, SAKaguchi K, Appella E et al. Identification of a human melanoma antigen recognized by tumor-infiltrating lymphocytes associated with in vivo tumor rejection. Proc Natl Acad Sci U S A 1994; 91: 6458-6462.

41. Escors D, Lopes L, Lin R, Hiscott J, Akira S, Davis RJ, Collins MK. Targeting dendritic cell signaling to regulate the response to immunization. Blood 2008; 111: 3050-3061.
42. Lang KS, Caroli CC, Muhm A, Wernet D, Moris A, Schittek B, Knauss-Scherwitz E, Stevanovic S, Rammensee HG, Garbe C. HLA-A2 restricted, melanocyte-specific CD8(+) T lymphocytes detected in vitiligo patients are related to disease activity and are predominantly directed against MelanA/MART1. J Invest Dermatol 2001; 116: 891-897.

43. Walker LS, Chodos A, Eggena M, Dooms H, AbBas AK. Antigen-dependent proliferation of CD4+ CD25+ regulatory $\mathrm{T}$ cells in vivo. $\mathrm{J}$ Exp Med 2003; 198: 249-258.

44. Kretschmer K, Apostolou I, Hawiger D, Khazaie K, Nussenzweig MC, von Boehmer H. Inducing and expanding regulatory $\mathrm{T}$ cell populations by foreign antigen. Nat Immunol 2005; 6: 12191227.

45. Liechtenstein T, Perez-Janices N, Bricogne C, LanNA A, Dufait I, Goyvaerts C et al. Immune modulation by genetic modification of dendritic cells with lentiviral vectors. Virus Res 2013; 176: 1-15.

46. Sakaguchi S, Yamaguchi T, Nomura T, Ono M. Regulatory $\mathrm{T}$ cells and immune tolerance. Cell 2008; 133: 775-787.

47. Inaba K, Inaba M, Romani N, Aya H, Deguchi M, Ikehara S, Muramatsu S, Steinman RM. Generation of large numbers of dendritic cells from mouse bone marrow cultures supplemented with granulocyte/macrophage colony-stimulating factor. J Exp Med 1992; 176: 1693-1702.

48. ZHou LJ, TeDDER TF. CD14+ blood monocytes can differentiate into functionally mature CD83+ dendritic cells. Proc Natl Acad Sci U S A 1996; 93: 2588-2592.

49. BRECKPOT K, Escors D. Dendritic cells for active anti-cancer immunotherapy: targeting activation pathways through genetic modification. Endocr Metab Immune Disord Drug Targets 2009; 9: 328-343.

50. Dullaers M, Breckpot K, Van Meirvenne S, Bonehill A, Tuyaerts S, Michiels A et al. Side-by-side comparison of lentivirally transduced and mRNA-electroporated dendritic cells: implications for cancer immunotherapy protocols. Mol Ther 2004; 10: 768-779.

51. Andreakos E, Williams RO, Wales J, Foxwell BM, Feldmann M. Activation of NF-kappaB by the intracellular expression of NF-kappaB-inducing kinase acts as a powerful vaccine adjuvant. Proc Natl Acad Sci U S A 2006; 103: 14459-14464.

52. Karwacz K, Bricogne C, MacDonald D, Arce F, Bennett CL, Collins M, Escors D. PD-L1 co-stimulation contributes to ligand-induced $\mathrm{T}$ cell receptor down-modulation on $\mathrm{CD} 8+\mathrm{T}$ cells. EMBO Mol Med. 2011; 3: 581-592. 
53. VAn Lint S, Goyvaerts C, Maenhout S, Goethals L, Disy A, BEnteyn D et al. Preclinical evaluation of TriMix and antigen mRNA-based antitumor therapy. Cancer Res 2012; 72: 1661-1671.

54. Gruber A, Kan-Mitchell J, Kuhen KL, Mukai T, Wong-Staal F. Dendritic cells transduced by multiply deleted HIV-1 vectors exhibit normal phenotypes and functions and elicit an HIV-specific cytotoxic T-lymphocyte response in vitro. Blood 2000; 96: 1327-1333.

55. Dyall J, Latouche JB, Schnell S, Sadelain M. Lentivirus-transduced human monocyte-derived dendritic cells efficiently stimulate antigen-specific cytotoxic $\mathrm{T}$ lymphocytes. Blood 2001; 97: 114-121.

56. Arrighi JF, Pion M, Wiznerowicz M, GeiJTenbeek TB, GaRcia E, ABraham S et al. Lentivirus-mediated RNA interference of DC-SIGN expression inhibits human immunodeficiency virus transmission from dendritic cells to T cells. $\mathrm{J}$ Virol 2004; 78: 10848-10855.

57. Yu Q, Kovacs C, Yue FY, Ostrowski MA. The role of the p38 mitogen-activated protein kinase, extracellular signal-regulated kinase, and phosphoinositide-3-OH kinase signal transduction pathways in CD40 ligand-induced dendritic cell activation and expansion of virus-specific CD8+ T cell memory responses. J Immunol 2004; 172: 6047-6056.

58. Karwacz K, Arce F, Bricogne C, Kochan G, Escors D. PD-L1 co-stimulation, ligand-induced TCR down-modulation and anti-tumor immunotherapy. Oncoimmunology 2012; 1: 86-88.

59. Pen JJ, De Keersmaecker B, Maenhout SK, Van Nuffel AM, Heirman C, Corthals J et al. Modulation of regulatory $\mathrm{T}$ cell function by monocyte-derived dendritic cells matured through electroporation with mRNA encoding CD40 ligand, constitutively active TLR4, and CD70. J Immunol 2013; 191: 1976-1983.

60. Klein C, Bueler H, Mulligan RC. Comparative analysis of genetically modified dendritic cells and tumor cells as therapeutic cancer vaccines. J Exp Med 2000; 191: 1699-1708.

61. Bodey B, Bodey B JR, Siegel SE, KaISER HE. Failure of cancer vaccines: the significant limi- tations of this approach to immunotherapy. Anticancer Res 2000; 20: 2665-2676.

62. Gitlitz BJ, Belldegrun AS, Zisman A, Chao DH, PANTUCK AJ, Hinkel A et al. A pilot trial of tumor lysate-loaded dendritic cells for the treatment of metastatic renal cell carcinoma. J Immunother 2003; 26: 412-419.

63. ZAROUR HM, KIRKWOOD JM. Melanoma vaccines: early progress and future promises.Semin Cutan Med Surg 2003; 22: 68-75.

64. Junttila MR, Li SP, Westermarck J. Phosphatase-mediated crosstalk between MAPK signaling pathways in the regulation of cell survival. FASEB J 2008; 22: 954-965.

65. Zhao Q, Wang X, Nelin LD, Yao Y, Matta R, Manson ME et al. MAP kinase phosphatase 1 controls innate immune responses and suppresses endotoxic shock. J Exp Med 2006; 203: 131-140.

66. Karwacz K, Mukherjee S, Apolonia L, Blundell MP, Bouma G, Escors D et al. Nonintegrating lentivector vaccines stimulate prolonged T-cell and antibody responses and are effective in tumor therapy. J Virol 2009; 83: 30943103.

67. Liechtenstein T, Perez-Janices N, Blanco-Luquin I, Goyvaerts C, Schwarze J, Dufait I et al. Anti-melanoma vaccines engineered to simultaneously modulate cytokine priming and silence PD-L1 characterized using ex vivo myeloid-derived suppressor cells as a readout of therapeutic efficacy. Oncoimmunology 2014; $3 ; 3$.

68. SHIN DS, Ribas A. The evolution of checkpoint blockade as a cancer therapy: what's here, what's next? Curr Opin Immunol 2015; 33: 2335.

69. Brahmer JR, Tykodi SS, Chow LQ, Hwu WJ, TopaLIAN SL, Hwu P et al. Safety and activity of anti-PD-L1 antibody in patients with advanced cancer. N Engl J Med 2012; 366: 2455-2465.

70. Topalian SL, Hodi FS, Brahmer JR, Gettinger SN, Smith DC, McDermott DF et al. Safety, activity, and immune correlates of anti-PD-1antibody in cancer. N Engl J Med 2012; 366: 2443-2454. 
